\title{
A new deep branch of eurasian mtDNA macrohaplogroup $M$ reveals additional complexity regarding the settlement of
} Madagascar

\author{
François-X Ricaut* ${ }^{* 1,2}$, Harilanto Razafindrazaka ${ }^{\dagger 1}$, Murray P Cox ${ }^{3}$, \\ Jean-M Dugoujon1, Evelyne Guitard ${ }^{1}$, Clement Sambo ${ }^{4}$, Maru Mormina ${ }^{5}$, \\ Marta Mirazon-Lahr ${ }^{5}$, Bertrand Ludes ${ }^{1,6}$ and Eric Crubézy ${ }^{1}$
}

\begin{abstract}
Address: ${ }^{1}$ CNRS FRE 2960, Laboratoire d'Anthropobiologie, Université de Toulouse, Toulouse III Paul sabatier, 37 allées Jules Guesde, 31073 Toulouse cedex 3, France, ${ }^{2}$ Center for Archaeological Sciences, Katholieke Universiteit Leuven, Celestijnenlaan $200 \mathrm{E}, 3001$ Heverlee, Belgium, ${ }^{3}$ Institute of Molecular BioSciences, Allan Wilson Centre for Molecular Ecology and Evolution, and the Bio-Protection Centre, Massey University, Palmerston North 4442, New Zealand, ${ }^{4}$ Ecole Normale Supérieure, Université de Toliara, Toliara, Madagascar, ${ }^{5}$ Leverhulme Centre for Human Evolutionary Studies, Henry Wellcome Building, Fitzwilliam Street, University of Cambridge, Cambridge CB2 1QH, UK and ${ }^{6}$ Laboratoire d'Anthropologie Moléculaire, Institut de Médecine Légale, 11 rue Humann, 67085 Strasbourg, France

Email: François-X Ricaut* - fx.ricaut@infonie.fr; Harilanto Razafindrazaka - razafindrazaka.harilanto@gmail.com; Murray P Cox - m.p.cox@massey.ac.nz; Jean-M Dugoujon - dugoujon@cict.fr; Evelyne Guitard - guitard@cict.fr; Clement Sambo - samboclement@yahoo.fr; Maru Mormina - mem50@cam.ac.uk; Marta Mirazon-Lahr - mbml1@cam.ac.uk; Bertrand Ludes - bertrand.ludes@iml-ulp.u-strasbg.fr; Eric Crubézy - crubezy.eric@free.fr

* Corresponding author †Equal contributors
\end{abstract}

Published: | 4 December 2009

BMC Genomics 2009, 10:605 doi:10.1 186/147|-2164-10-605
Received: 9 June 2009

Accepted: I4 December 2009

This article is available from: http://www.biomedcentral.com//47/-2/64//0/605

(C) 2009 Ricaut et al; licensee BioMed Central Ltd.

This is an Open Access article distributed under the terms of the Creative Commons Attribution License (http://creativecommons.org/licenses/by/2.0), which permits unrestricted use, distribution, and reproduction in any medium, provided the original work is properly cited.

\begin{abstract}
Background: Current models propose that mitochondrial DNA macrohaplogroups $M$ and $N$ evolved from haplogroup L3 soon after modern humans left Africa. Increasingly, however, analysis of isolated populations is filling in the details of, and in some cases challenging, aspects of this general model.

Results: Here, we present the first comprehensive study of three such isolated populations from Madagascar: the Mikea hunter-gatherers, the neighbouring Vezo fishermen, and the Merina central highlanders $(n=266)$. Complete mitochondrial DNA genome sequences reveal several unresolved lineages, and a new, deep branch of the out-of-Africa founder clade $M$ has been identified. This new haplogroup, M23, has a limited global distribution, and is restricted to Madagascar and a limited range of African and Southwest Asian groups.
\end{abstract}

Conclusions: The geographic distribution, phylogenetic placement and molecular age of M23 suggest that the colonization of Madagascar was more complex than previously thought.

\section{Background}

The dominant and widely accepted model of modern human origins proposes that our species originated in Africa 150,000 years ago (kyr), and after environmental and/or cultural changes, emerged into Eurasia 85-55 kyr along the Indian Ocean coast toward Australasia (i.e., the Southern Dispersal Route). In terms of human mitochondrial DNA (mtDNA) patterns, this dispersal apparently occurred relatively soon after the appearance of macrohaplogroup L3 in Africa ( $85 \mathrm{kyr}$ ). The two non-African 
lineages (macrohaplogroups $\mathrm{M}$ and $\mathrm{N}$ ) diverged shortly afterwards, either just after modern humans left Africa [16], or perhaps within Africa slightly earlier, as suggested by an ongoing debate surrounding the early geographical origin of macrohaplogroup M [7-12]. However, beyond this broad-scale view, the settlement patterns of many individual regions are still poorly understood, although some of them are key areas for investigating our species' recent history - either because of their location (e.g., remote and/or close to major dispersal routes), or because they contain isolated or relict populations (e.g., Australia, India, Indonesia). This is the case for Madagascar. The favoured settlement model suggests that the first human groups to reach the island did so extremely recently, around $1.5-2 \mathrm{kyr}$, when there is clear archaeological evidence of human occupation $[13,14]$. Furthermore, the genetic, cultural, and linguistic characteristics of the Malagasy indicate that people from both Africa, and Island Southeast Asia played a major role in the colonization of the island, ultimately resulting in a population genetically and linguistically admixed from African and Southeast Asian sources [15-20]. Still, major issues remain unresolved regarding the origin and relative contributions of each founder population to the extant Malagasy gene pool.

The earliest archaeological evidence on the island is controversial. Hippopotamus bones with cut-marks and evidence of human processing from iron tools have been found in the Mikea Forest, in Madagascar's Southwest, dating to 2 kyr [21]. Later archaeological sites, now containing pottery, have been variously dated from the $4^{\text {th }}$ to the $8^{\text {th }}$ centuries $\mathrm{AD}$. Therefore, the island seems to have been visited at least intermittently by Africans prior to the arrival of Austronesian-speaking maritime travellers from Island Southeast Asia sometime around the $7^{\text {th }}$ or $8^{\text {th }}$ centuries $\mathrm{AD}[18,19,22-25]$. This settlement pattern is further supported by dated faunal extinctions, as well as palaeoenvironmental evidence of deforestation indicated by a decrease in tree pollen and an increase in small charcoal pieces in soil sediments $[14,24,26]$.

The ethnographic evidence is equally complex. All Malagasy today speak a Malayo-Polynesian language, also called Malagasy, which is most closely related to a language spoken in the Barito River basin of Southeast Borneo, Indonesia $[18,19,22]$. Malagasy contains a number of loan words of African Bantu origin, but these have apparently been borrowed from the Swahili/Sabaki group of languages, and thus form part of the cultural exchange that took place during more recent Indian Ocean trade $[22,27]$. However, oral tribal traditions suggest the earlier presence of a people called Vazimba, who spoke a nonMalagasy language. Pockets of people still known as Vazimba exist among the island's fishermen, and their nonMalagasy lexicon has also been argued to be of Bantu origin $[23,26]$. Furthermore, two groups of hunter-gatherers still live on the island - the Beosy and the Mikea, who inhabit the forests of Southwestern Madagascar, and who were recognised as having African affinity as early as the $16^{\text {th }}$ century $[24,26]$.

This paper presents the first comprehensive study of the mtDNA diversity of three Malagasy speaking groups, the Mikea hunter-gatherers, the neighbouring Vezo fishermen, and the Merina central highlanders, and reveals new details regarding the early period of Madagascar's complex history.

\section{Results and Discussion}

Analysis of mtDNA from 266 Malagasy individuals (Table 1 ) is broadly consistent with previous genetic studies [15$17,20]$. We see a combination of Southeast Asian and African lineages that are likely to trace back to the initial settlement of the island around the $7^{\text {th }}$ century AD. However, our results based on complete mitochondrial genomes also revealed the presence of five novel mtDNA lineages that cluster into a previously uncharacterized clade whose geographic distribution seems to be restricted to the island of Madagascar (Additional files 1 and 2). The age estimates for this clade and its main sub-branches are shown in Table 2.

Of the five novel lineages one was found among the Mikea hunter-gatherers (at a frequency $<1 \%$ ) and four among the Vezo fishermen (at a frequency of $4 \%$ ) (table 1 , highlighted). Comparative phylogenetic analysis of worldwide mtDNA genomes confirmed the clustering of

Table I: Inferred frequencies of mtDNA haplogroups in three Malagasy populations: Merina, Vezo, and Mikea.

\begin{tabular}{|c|c|c|c|c|c|c|c|c|}
\hline \multirow[t]{2}{*}{ Malagasy population } & \multicolumn{8}{|c|}{ mtDNA haplogroups } \\
\hline & L4, L3, L2, LI & M23 & M7c3 & Elala & M46 & $M^{*}$ & $\mathbf{F} 3 \mathbf{b}$ & B4alala \\
\hline Mikea (127) & 71 & $\mathbf{I}$ & 8 & 13 & 3 & 9 & 5 & 17 \\
\hline Vezo $(|0|)$ & 47 & 4 & 9 & 5 & 5 & 3 & 6 & 22 \\
\hline Merina (38) & 13 & 0 & 0 & 4 & 2 & 0 & 0 & 19 \\
\hline Total (266) & $|3|$ & 5 & 17 & 22 & 10 & 12 & 11 & 58 \\
\hline
\end{tabular}

Note. Sequence classification into mtDNA haplogroups was based on accepted nomenclature as detailed in the Materials and Methods section. M* include lineages that were not complete sequenced and thus could not be assignated to currently published haplogroups. 
Table 2: Molecular dates estimated for the TMRCA and founder of Malagasy haplogroups M23, M23a and M23b from coding region information.

\begin{tabular}{|c|c|c|c|c|c|c|c|c|c|c|c|c|c|c|c|}
\hline \multirow[b]{2}{*}{ Haplogroup } & \multicolumn{8}{|c|}{ Coding Region nt577-nt| 6022} & \multicolumn{7}{|c|}{ Synonymous Mutations } \\
\hline & $\mathbf{n}$ & $\rho$ & $\sigma$ & $\begin{array}{l}\text { Mutation } \\
\text { rate }\end{array}$ & $\begin{array}{c}\text { TMRC } \\
\text { A }\end{array}$ & $95 \% \mathrm{Cl}$ & $\begin{array}{c}\text { Founder } \\
\text { age }\end{array}$ & $95 \% \mathrm{Cl}$ & $\rho$ & $\sigma$ & $\begin{array}{l}\text { Mutation } \\
\text { rate }\end{array}$ & $\underset{\mathbf{A}}{\text { TMRC }}$ & $95 \% \mathrm{Cl}$ & $\begin{array}{c}\text { Founder } \\
\text { age }\end{array}$ & $95 \% \mathrm{Cl}$ \\
\hline \multirow[t]{2}{*}{ M23 } & 5 & 1.8 & 0.6 & (I) & 9,300 & $\begin{array}{l}3,200- \\
15,300\end{array}$ & 65,800 & $\begin{array}{l}49,700- \\
81,900\end{array}$ & 1.2 & 0.49 & $(2)$ & 8,100 & $\begin{array}{l}I, 600- \\
14,600\end{array}$ & 62,200 & $\begin{array}{l}44,200- \\
80,200\end{array}$ \\
\hline & & & & & & & & & 1.2 & 0.49 & (3) & 9,400 & $\begin{array}{l}1,900- \\
17,000\end{array}$ & 72,500 & $\begin{array}{l}51,500- \\
93,500\end{array}$ \\
\hline \multirow[t]{2}{*}{ M23a } & 1 & 2 & $\mathrm{I} .4 \mathrm{I}$ & (I) & 10,300 & $0-24,400$ & & & 1 & I & $(2)$ & 6,800 & $0-20,000$ & & \\
\hline & & & & & & & & & 1 & I & (3) & 7,600 & $0-23,300$ & & \\
\hline \multirow[t]{2}{*}{ M23b } & 4 & 0.75 & 0.43 & (I) & 3,900 & $0-8,200$ & & & 0.25 & 0.25 & (2) & $\mathrm{I}, 700$ & $0-5,000$ & & \\
\hline & & & & & & & & & 0.25 & 0.25 & (3) & 2,000 & $0-5,800$ & & \\
\hline
\end{tabular}

Mutation rate references: (I) One substitution per 5,139 years [56]; (2) One synonymous transition per 6,764 years [36]; (3) One synonymous mutation (transition or transversion) per 7,884 years [35]. Founder Age: $\rho=12,8 ; \sigma=1.6$ with the Mishmar and colleagues approach [56], and $\rho=$ 9.2; $\sigma=1.36$ with the Kivisild and colleagues [36] and Soares and colleagues [35] approaches. TMRCA, 95\% confidence intervals (Cl), and founder age are given in years.

these five lineages into a deep-rooted branch within macrohaplogroup M, which we name M23. This new branch carries all the diagnostic polymorphisms of macrohaplogroup $\mathrm{M}$ as well as a substantial series of mutations that separates it from the root of macrohaplogroup M (Figure 1). Haplogroup M23 is characterized by 11 coding region mutations (viz. 2706-8360-9438-9545-10142-1029511569-11899-12279-12618-15025) and 8 control region mutations (viz. 152-195-204-417-533-16263-1631116519) (Figure 1). The absence of a polymorphism at 2706 in the five M23 carriers indicates a back mutation, and we consider this position another basal polymorphism of haplogroup M23. Haplogroup M23 splits into two branches, M23a and M23b. The former is represented by one individual from the Vezo group whilst the latter, defined by a substitution at np 8188 encompasses all the remaining Vezo lineages and is also present in the Mikea.

So far we found no convincing association of M23 with any known $\mathrm{M}$ branches. None of the diagnostic coding region mutations of M23 overlaps with the diagnostic markers in other $\mathrm{M}$ haplogroups that emerge directly from the root of macrohaplogroup M (see van Oven and Kayser [28]). While some control region mutations $(152,195$, 16311,16263 and 16519) are shared by other deeprooted M haplogroups (e.g., M1, M28, M29 and M46), these positions are known to be recurrent and cannot be safely considered as linking M23 to other haplogroups within macrohaplogroup $M$. This confirms the robustness of our phylogenetic reconstruction, and the basal position of M23 within M.

More detailed examination of the phylogeny, geographic distribution, and molecular dating of the M23 lineage reveals three further key points:

(1) As noted before, the position of M23 at the root of macrohaplogroup M indicates that M23 is a deep branch of the human mtDNA phylogeny. The length of the M23 branch suggests either strong genetic drift effects or that this cluster may encompass further branches yet to be identified. Indeed, a relatively small proportion of $m t D N A$ variation has been surveyed in the putative areas of origin of M23. Therefore more extensive sampling is needed to refine the overall geographic distribution and branching structure of this clade, However, the fact that this clade has no specific link to other known branches within macrohaplogroup $M$ suggests a deep-rooted ancestry, possibly tracing back to the Out of Africa event. Such a deep root is also shared with many other lineages that emerged independently from the root of macrohaplogroup $M$. These lineages are especially prevalent in South Asia [2,29-31]. This general pattern has been interpreted as supporting the view of a rapid dispersal of modern humans at the time of the out-of-Africa exodus, followed by a long period of isolation resulting in non-overlapping distributions of derived $M$ haplogroups in relict or isolated populations/regions along the dispersal route. Thus, our results suggest that the Mikea hunter-gatherers and Vezo fishermen of Madagascar descend, if only in very small part $(\leq 4 \%)$, from one such deep-rooted, isolated population.

(2) M23 lineages have an extremely restricted geographic distribution. A survey of all complete mtDNA sequences reported in the literature (>6,700 sequences; http:// www.phylotree.org/) could not detect M23 sequences anywhere outside Madagascar. Moreover, the screening of control region polymorphisms that are diagnostic for M23 against a larger global panel of mtDNA control region variants confirmed that the M23 control region motif is indeed rare, as only four individuals shared the 13 control region diagnostic mutations for M23 (Additional file 1). Although comparative analysis based only on the first hypervariable sequence (HVS1) reveals a few more individuals that share the four HVS1 mutations of M23 


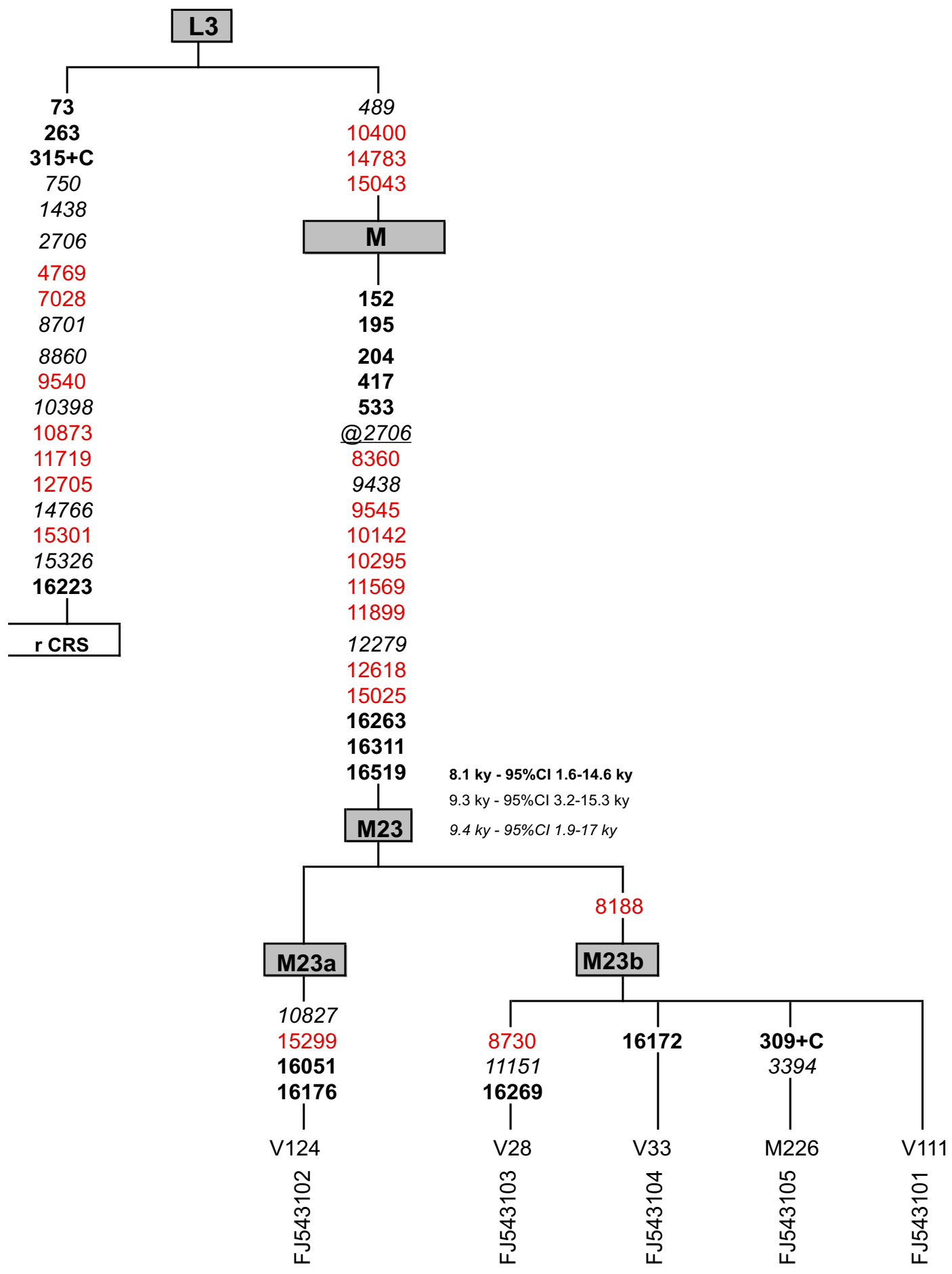

Figure I

Phylogenetic tree constructed from complete mtDNA sequences for five Malagasy individuals. $M$ and $V$ represents the Mikea and Vezo populations, respectively. Mutations were scored relative to the rCRS [42]. Numbers along links refer to nucleotide positions. A plus sign (+) indicates an insertion. Recurrent mutations in the phylogeny are underlined. The prefix "@" indicates back mutations. Control region mutations are in bold, synonymous transitions are shown in red, and nonsynonymous mutations are listed in italic. TMRCA estimates were calculated as in $[35,36,56]$, presented in italic, bold and regular font, respectively, and are presented in units of thousands of years before present. 
(16223, 16263, 16311 and 16519), these nucleotide positions are known to be fast-mutating and recurrent, and consequently cannot be considered diagnostic of haplogroup M23 (Additional files 1, 2 and 3). Interestingly, three of the four individuals sharing the 13 control region mutations for M23 are African Americans who are likely to trace their ancestry to sub-Saharan Africans, although no M23 carriers have been detected on mainland Africa itself (Additional files 2 and 3). The fourth individual is from the Arabian Peninsula (Dubai, United Arab Emirates), a region placed in Southwest Asia which has a long history of interactions with Africa, probably dating back to the dispersal of modern human along the southern dispersal route $[3,4,6]$. The modern population of Dubai has a genetic composition strongly influenced by femalemediated gene flow from sub-Saharan Africa, as well as migration from South Asian populations [32], which have the highest observed levels of basal $M$ lineages $[2,29,31,33]$. Although we have only detected four individuals potentially affiliated to M23, they are likely to descend from an African and/or Southwest Asian source, again placing the origin of M23 somewhere between these two regions. Unfortunately, lacking genealogical records for these four individuals, we cannot confirm their maternal African origin, and without additional mtDNA coding region information, the link with African populations remains highly speculative. However, if confirmed, this finding would suggest that the origin and dispersal of M23 lineages is restricted to the circum-Arabia/northwestern Indian Ocean regions.

(3) Despite the limitations of molecular dating [34], the estimated founder age of macrohaplogroup $\mathrm{M}$ using the M23 branch considered alone is $62-73 \mathrm{kyr}$ (95\% confidence interval, 44-94 kyr) (Table 2). This conforms to the revised age estimate of macrohaplogroup $M$ [35], and is slightly older than the proposed date for the dispersal of anatomically modern humans from Africa, as well as the population expansion accompanying it $[2-4,33,36]$. The time to the most recent common ancestor (TMRCA) of M23 has been estimated at $9.4 \mathrm{kyr}$ (95\% confidence interval: 1.9-17 kyr) using a recently improved control region mutation rate [35] (Table 2), in broad agreement with dates obtained using previous coding region mutation rates (Table 2). Considering that a demographic expansion may predate a geographic one, it is worth noting that the lower age estimates of M23, and especially of its subclade M23b, fall clearly within the Holocene (1.7-3.9 kyr; $95 \%$ confidence interval, $0-8.2 \mathrm{kyr}$ ). Although this is broadly consistent with a late Holocene date for the initial settlement of Madagascar [14,18,19,21-25] and the concomitant demographic/geographic expansions, the large confidence intervals add uncertainty to the dispersal date of M23 and leave open the possibility that this rare lineage may represent an early pre-Austronesian expansion into Madagascar.
The presence of the M23 clade among the Malagasy Vezo fishermen and Mikea hunter-gatherers provides additional mtDNA evidence upon which a better picture of the colonization of Madagascar can be built. However, open questions remain, including the geographic origin of M23, and the time and mode of its spread into Madagascar. These outstanding issues can only be partially investigated with the currently available data. The M23 lineage is not present in any of the putative parental populations of the Malagasy (Africans and Island Southeast Asians), suggesting either its absence from these populations, or that it is so exceedingly rare there that it has not yet been detected [17,37-40] (Additional files 1 and 2). Indeed, relative to their genetic diversity, Africans and Southeast Asians have not been widely sampled, although Borneo (the likely source of the Austroensian expansion into Madagascar) has been relatively well surveyed, and a high number of published mtDNA sequences $(\mathrm{n}=157)$ is currently available from this area [38]. Nonetheless, M23 lineages have not been identified in this region. Even if M23 is as rare in Borneo as it is in Madagascar $(1.9 \%)$, the probability of it being detected there is high: $P(\mathrm{M} 23 \mid \mathrm{n}$, freq) $=0.95$. However, the extreme population structure of Indonesia [41] may mean that M23 is restricted to populations that have not yet been sufficiently sampled, or at all.

An alternative hypothesis is that the M23 motif developed in situ in Madagascar, either completely or partially. If this is the case, a pre-M23 lineage should have evolved more or less in isolation within the founder population that later participated in the colonization of Madagascar.

The identification of four individuals of African and Southwest Asian origin who share the 13 diagnostic control region mutations for M23 pinpoints these regions as potential sources for M23. Whilst, the data does not allow us to make clear phylogeographic inferences regarding M23 origin, our results may provide some evidence of ancient contacts across the Indian Ocean involving Africa, Madagascar and South Asia. The deep-rooted topology of M23 and its age estimate coupled with its very restricted distribution within Madagascar, makes unlikely its presence in the island as a result of recent contacts, and is more in agreement with the patterns of human contacts across the Arabian Sea and the Indian Ocean, which predated the Austronesian expansion into Madagascar $[24,27]$.

Whilst more extensive screening of the putative parental populations in Africa and South Asia will help to ascertain the geographic origin and distribution of M23, our initial examination of Malagasy mtDNA diversity suggests that the origin of M23 lineages may be found in the circumArabia/northwestern Indian Ocean regions and that their arrival to Madagascar may pre-date the Austronesian set- 
tlement of the island. This lends support to oral tribal traditions stressing the earlier presence of non-Malagasy speakers (e.g. Vazimba; $[23,24,26])$ and re-emphasizes the importance and complexity of the circum-Arabia and Indian Ocean corridor since the late Pleistocene.

\section{Conclusion}

The finding of a new deep branch of the out-of-Africa founder M, named as M23, in fishermen and hunter-gatherers from Southwestern Madagascar raises many questions regarding both the clade's origin and its role in the settlement of Madagascar. Extant data cannot provide unequivocal evidence for the origin of $\mathrm{M} 23$, although the current distribution of macrohaplogroup $M$ points to Southeast Asia as the most likely source region. Additional archaeological surveys, population sampling from South Asia and East Africa/Madagascar, and further phylogeographic analyses are necessary to ascertain the exact time and place of origin of this clade, as well as its geographic dispersal. However, this novel mtDNA branch already provides a new suite of diagnostic markers to expand the search for its geographical and temporal origin.

\section{Methods \\ Population samples}

The samples analyzed in this study were taken from our Malagasy assemblage, which was collected in field seasons 2007-2008. The samples were obtained with informed consent, and were approved by Human Subjects' Ethics Committees in Madagascar, and at the University of Toulouse, France. Buccal cells and peripheral blood were sampled from unrelated individuals, and stored in EDTA Vaccutainer tubes. Subjects were surveyed for language affiliation, current residence, familial birthplaces, and a short genealogy of four generations to establish regional ancestry. A total of 266 DNA samples were analyzed from three ethnic groups: 127 Mikea (hunter-gatherers located in the Southwest), 101 Vezo (semi-nomadic fishermen also located in the Southwest), and 38 Merina (highlanders from central Madagascar).

\section{DNA extraction, amplification and sequencing}

DNA was extracted using a standard phenol-chloroform method, ethanol precipitated, and stored in Tris EDTA at $-20^{\circ} \mathrm{C}$ until further use. Analysis proceeded in three phases.

First, we amplified and sequenced hypervariable segments 1 and 2 (HVS1 and HVS2) of the mitochondrial DNA control region using primers: L15973 (5'-AACTCCACCATTAGCACCCA-3'), and H296 (5'TCTGTAGTATTGTTTTTAAAAGG-3'). Samples were sequenced by the Genopole Toulouse Sequencing Service http://www.genotoul.fr/ on an ABI PRISM 3730 Genetic Analyzer. Sequences were edited and aligned against the revised Cambridge reference sequence (rCRS) [42] using BioEdit 7.0.9 [43]. Deviations from the rCRS were confirmed by checking electropherograms manually.

Second, for samples not definitively assigned to a known haplogroup from HVS1 and HVS2 sequence variation alone, we screened for mutations defining macrohaplogroups L3 (-10871 MnlII), M (+10397 AluI; +10394 DdeI), and N (-10397 AluI; -10394 DdeI). Then, depending on the presence or absence of these sites, additional RFLPs were surveyed to identify other haplogroups common in Southeast Asia: E (-7598 HhaI); E1 (+10834 MseI); D (5176 AluI); M7 (+9820 Hinfl); M7c3 (+3606 Sau96 I); M7c1 (+ 3882 BsaI), all within macrohaplogroup M; and F (+10306 BspmI); F3 (+10319 Tsp509 I) and B4a1a (+6719 NlaIII), all within macrohaplogroup N. To confirm affiliation of samples to haplogroup B, the 9-base pair intergenic region $V$ deletion [44] was amplified using primers L8196 and H8297 [45].,

Third, 5 representative samples from the 17 samples remaining with uncertain phylogenetic status (i.e., that could not be assigned to currently recognized haplogroups) were selected for complete mtDNA sequencing by the Genomic Analysis Technology Core (GATC) at the University of Arizona http://uagc.arl.arizona.edu/. The 12 remaining samples were not completely sequenced, and consequently we do not know whether they belong to M23. Using twenty-eight pairs of primers, overlapping fragments of forward and reverse DNA strands were amplified and sequenced. Sequences were edited and aligned as described above. The five complete mtDNA sequences have been deposited in the GenBank database (Accession Numbers: FJ543101-FJ543105).

We utilized strict quality control to avoid errors and artefacts (e.g., base shift, reference bias, phantom mutations, errors in base scoring, and artifactual recombination) as proposed by Bandelt et al. [46]: (i) each base pair was determined with both forward and reverse primers ensuring overlapping sequencing of both strands; (ii) we rechecked all sequence variations by manual observation of sequence electropherograms; (iii) as well as checking for any incongruence with results obtained from PCR. Moreover, we checked that all sequence variations observed have previously been reported http:// www.mitomap.org/, and that haplogroup and sub-haplogroup motifs were fully represented.

\section{Statistical analysis \\ Geographic distribution}

To estimate the geographic distribution of M23 lineages, we compared the five Malagasy M23 complete mtDNA sequences with more than 6,700 complete mtDNA sequences compiled by van Oven and Kayser http:// 
www.phylotree.org/; [28]), a dataset that contains all of the complete mtDNA genomes available to date. However, as whole genome sequences are rare for some regions and populations, especially those known to have high genetic diversity (e.g., Eastern Africa, Southern India, Indonesia), we also performed a comparative analysis using partial or entire mtDNA control region sequences. (Note that we discarded indels at position 309, 315, 573, and 16193). This comparison was made by screening an in-house database of 43,849 HVS1 sequences collated from the literature, as well as several web-based mtDNA databases: (1) DDBJ/EMBL/GENBANK international nucleotide sequence database; (2) mtDNAmanager http:/ Lmtmanager.yonsei.ac.kr/[47]; (3) The EMPOP database http://www.empop.org/; [48]); (4) the Genographic Project Open Resource Mitochondrial DNA database [49]; and (5) HvrBase++ http://www.hvrbase.org; [50]. This comparative analysis allowed us to survey most of the HVS sequences published thus far. However, although providing larger numbers of samples for analysis, this comparison is limited by higher rates of homoplasy and back mutation in the mtDNA hypervariable sequences compared to coding regions. This can lead to evolutionary convergence, and therefore confound unrelated sequences that are "identical by state" (IBS) as opposed to "identical by descendent" (IBD) [49].

\section{Phylogeny reconstruction}

Sequence classification into mtDNA haplogroups was based on accepted nomenclature (e.g., $[1,9,29$ 31,36,37,40,51-53]; http://www.phylotree.org/; http:// mtmanager.yonsei.ac.kr/). The phylogenetic tree was reconstructed from median-joining networks rooted to L3 using Network 4.2.0.1 http://www.fluxus-engineer ing.com/[54]. The tree was checked manually to resolve homoplasies.

\section{Molecular dating}

TMRCA estimates were calculated using the rho $(\rho)$ statistic and its standard deviation (SD) [55] with three previously described mutation rates based on coding region mutations. Two mutation rates were calculated using estimated substitution rates; one of $3.5 \times 10^{-8}$ mutations/site/ year for protein-coding synonymous changes, which yields 6,764 years per synonymous transition [36], and another of one synonymous mutation (including transitions and transversions) every 7,884 years from the recently improved mitochondrial molecular clock published by Soares and colleagues [35]. Data from the MAMMAG website http://mammag.web.uci.edu/bin/view/ Main/WebHome was used to identify synonymous transitions. The third mutation rate was based on substitution changes for the entire coding region $\left(1.26 \times 10^{-8}\right.$ mutation/site/year), which is equivalent to 5,139 years per mutation [56] between positions 577 and 16023 of the
rCRS [42]. All three rates were calibrated by comparison to chimpanzee sequences using a divergence time between human and chimpanzee mtDNAs of 6.5 million years. Dates estimated from synonymous changes are likely to be more robust, as these changes are mostly selectively neutral [36]. It is worth noting that due to the ongoing debate regarding the true mutation rate $[36,57]$, and the limitations of the rho $(\rho)$ statistic method of molecular dating [34], the conversion of age estimates in mutations into ages in years and the estimation of associated error values are to be considered approximations only. These dates should be interpreted cautiously.

\section{Authors' contributions}

JMD, EC, BL, FXR, and CS designed research; HR and EG performed research; FXR, HR, MPC, and EC analyzed data; FXR, HR, MPC, MM and MML wrote the paper. All authors read and approved the final manuscript.

\section{Additional material}

\section{Additional file 1 \\ Distribution of diagnostic mtDNA control region polymorphisms in haplogroup M23 (73G 152C 195C 204C 263G 315.1C 417A 489C 533G 16223T 16263C 16311C 16519C) from available databases. The table displays the occurrence of the mtDNA control region diagnostic polymorphisms of haplogroup M23 in six mtDNA databases ( $\leq 1 \mathrm{mis}$ - match). \\ Click here for file \\ [http://www.biomedcentral.com/content/supplementary/1471- 2164-10-605-S1.XLS] \\ Additional file 2 \\ Distribution of HVS1 polymorphisms defining haplogroup M23 within sub-Saharan African populations. The table displays the occur- rence of the M23 HVS1 motif in 7,262 sub-Saharan Africans. \\ Click here for file \\ [http://www.biomedcentral.com/content/supplementary/1471- 2164-10-605-S2.XLS]}

\section{Additional file 3}

Reference list for the supplemental citations in Additional files 1 and2. Click here for file

[http://www.biomedcentral.com/content/supplementary/14712164-10-605-S3.DOC]

\section{Acknowledgements}

We thank Toomas Kivisild (University of Cambridge, UK), Tim Thomas (University of Otago, New Zealand), and Nicolas Brucato (University of Toulouse, France) for their helpful comments on a previous version of this paper, and Daniel Montagnon (University of Strasbourg, France) for statistical assistance. We are also grateful to three anonymous reviewers of this manuscript for their helpful comments. This research was supported by grants from the French Department of Research, and the CNRS-départment EDD. The five complete mtDNA sequences reported in this paper have been deposited in the GenBank database (Accession Numbers: Fj54310I-Fj543105). 


\section{References}

I. Behar DM, Villems R, Soodyall H, Blue-Smith J, Pereira L, Metspalu E, Scozzari R, Makkan H, Tzur S, Comas D, et al.: The dawn of human matrilineal diversity. Am J Hum Genet 2008, 82(5): I I 30- I I 40.

2. Macaulay V, Hill C, Achilli A, Rengo C, Clarke D, Meehan W, Black burn J, Semino O, Scozzari R, Cruciani F, et al:: Single, rapid coasta settlement of Asia revealed by analysis of complete mitochondrial genomes. Science 2005, 308(5724): I034- 1036.

3. Forster P, Matsumura S: Evolution. Did early humans go north or south? Science 2005, 308(5724):965-966.

4. Mellars P: Going east: new genetic and archaeological perspectives on the modern human colonization of Eurasia. Science 2006, 3 I 3(5788):796-800

5. Atkinson QD, Gray RD, Drummond AJ: Bayesian coalescent inference of major human mitochondrial DNA haplogroup expansions in Africa. Proc Biol Sci 2009, 276( I 655):367-373.

6. Field JS, Lahr MM: Assessment of the southern dispersal: GISbased analyses of potential routes at oxygen isotopic stage. Journal of World Prehistory 2005, I 9(I): I-45.

7. Rosa A, Brehm A, Kivisild T, Metspalu E, Villems R: MtDNA profile of West Africa Guineans: towards a better understanding of the Senegambia region. Ann Hum Genet 2004, 68(Pt 4):340-352.

8. Kivisild T, Reidla M, Metspalu E, Rosa A, Brehm A, Pennarun E, Parik J, Geberhiwot T, Usanga E, Villems R: Ethiopian mitochondrial DNA heritage: tracking gene flow across and around the gate of tears. Am J Hum Genet 2004, 75(5):752-770

9. Olivieri A, Achilli A, Pala M, Battaglia V, Fornarino S, Al-Zahery N, Scozzari R, Cruciani F, Behar DM, Dugoujon JM, et al:: The mtDNA legacy of the Levantine early Upper Palaeolithic in Africa. Science 2006, 3 |4(5806): I767-I770.

10. Gonzalez AM, Larruga JM, Abu-Amero KK, Shi Y, Pestano J, Cabrera VM: Mitochondrial lineage MI traces an early human backflow to Africa. BMC Genomics 2007, 8:223.

II. Passarino G, Semino O, Quintana-Murci L, Excoffier L, Hammer M, Santachiara-Benerecetti AS: Different genetic components in the Ethiopian population, identified by mtDNA and Y-chromosome polymorphisms. Am J Hum Genet I998, 62(2):420-434.

12. Quintana-Murci L, Semino O, Bandelt HJ, Passarino G, McElreavey K Santachiara-Benerecetti AS: Genetic evidence of an early exit of Homo sapiens sapiens from Africa through eastern Africa Nat Genet 1999, 23(4):437-44I.

13. Dewar RE, Wright HT: The culture History of Madagascar. Journal of World Prehistory 1993, 7(4):

14. Burney DA, Burney LP, Godfrey LR, Jungers WL, Goodman SM, Wright HT, Jull AJT: A chronology for late prehistoric Madagascar. Journal of Human Evolution 2004, 47( I-2):25-63.

15. Hurles ME, Sykes BC, Jobling MA, Forster P: The dual origin of the Malagasy in Island Southeast Asia and East Africa: evidence from maternal and paternal lineages. Am J Hum Genet 2005, 76(5):894-901.

16. Soodyall $H$, Jenkins $T$, Stoneking M: 'Polynesian' mtDNA in the Malagasy. Nat Genet 1995, I0(4):377-378.

17. Cox MP: Genetic Patterning at Austronesian Contact Zones. In PhD thesis University of Otago; 2003.

18. Adelaar AK: "Asian roots of the Malagasy: a linguistic perspective". Volume 15I. Leiden: Bijdragen tot de Taal-, Land- en Volkenkunde; 1995:325-356

19. Dahl OC: Malgache et Maanjan. Une comparaison linguistique. Oslo, Egede-Institutet; 1951:408.

20. Tofanelli S, Bertoncini S, Castri L, Luiselli D, Calafell F, Donati G, Paoli $G$ : On the origins and admixture of Malagasy: new evidence from high-resolution analyses of paternal and maternal lineages. Mol Biol Evol 2009, 26(9):2 I09-2I 24.

21. Macphee RDE, Burney DA: Dating of Modified Femora of Extinct Dwarf Hippopotamus from Southern Madagascar Implications for Constraining Human Colonization and Vertebrate Extinction Events. J Archaeol Sci I99I, I 8(6):695-706.

22. Blench RDM: The Austronesians in Madagascar and on the East African Coast: Surveying the Linguistic Evidence for Domestic and Translocated Animals. paper presented at the International Conference on Austronesian Languages Palawan: I 7-20 January 20062006.

23. Vérin P: The History of civilisation in North Madagascar. Rotterdam: Balkema; 1986.
24. Blench MR: New palaeo-zoogeographical evidence for the settlement of Madagascar. Azania XLII: Journal of the British Institute in Eastern Africa 2007, 42:69-82.

25. Adelaar A: Towards an integrated theory about the Indonesian migrations to Madagascar. In Ancient Human Migrations: An Interdisciplinary Approach Edited by: P.N. Peregrine IP, Feldman M. Salt Lake City: University of Utah Press; 2009.

26. Stiles D: The Mikea hunter-gatherers of southewestern Madagascar: ecology and socioeconomics. African Study Monographs 1998, I9(3): 127-148.

27. Fuller DQ, Boivin N: Crops, cattle and commensals across the Indian Ocean: Current and potential archaeobiological evidence. In Plants and People in the Western Indian Ocean Edited by CEROI in press.

28. Van Oven M, Kayser M: Updated comprehensive phylogenetic tree of global human mitochondrial DNA variation. Hum Mutat 2009, 30(2):E386-394.

29. Thangaraj K, Chaubey G, Singh VK, Vanniarajan A, Thanseem I, Reddy $A G$, Singh L: In situ origin of deep rooting lineages of mitochondrial Macrohaplogroup 'M' in India. BMC Genomics 2006, 7:|5|

30. Hudjashov G, Kivisild T, Underhill PA, Endicott P, Sanchez J], Lin AA, Shen P, Oefner P, Renfrew C, Villems R, et al.: Revealing the prehistoric settlement of Australia by $\mathbf{Y}$ chromosome and mtDNA analysis. Proc Natl Acad Sci USA 2007, I 04(2 I ):8726-8730.

31. Sun C, Kong QP, Palanichamy MG, Agrawal S, Bandelt HJ, Yao YG, Khan F, Zhu CL, Chaudhuri TK, Zhang YP: The dazzling array of basal branches in the mtDNA macrohaplogroup $M$ from India as inferred from complete genomes. Mol Biol Evol 2006, 23(3):683-690.

32. Alshamali F, Brandstatter A, Zimmermann B, Parson W: Mitochondrial DNA control region variation in Dubai, United Arab Emirates. Forensic Sci Int Genet 2008, 2(I):e9-10.

33. Kumar S, Padmanabham PB, Ravuri RR, Uttaravalli K, Koneru P, Mukherjee PA, Das B, Kotal M, Xaviour D, Saheb SY, et al.: The earliest settlers' antiquity and evolutionary history of Indian populations: evidence from M2 mtDNA lineage. BMC Evol Biol 2008, 8:230

34. Cox MP: Accuracy of molecular dating with the rho statistic: deviations from coalescent expectations under a range of demographic models. Hum Biol 2008, 80(4):335-357.

35. Soares P, Ermini L, Thomson N, Mormina M, Rito T, Rohl A, Salas A Oppenheimer S, Macaulay V, Richards MB: Correcting for purifying selection: an improved human mitochondrial molecular clock. Am J Hum Genet 2009, 84(6):740-759.

36. Kivisild T, Shen P, Wall DP, Do B, Sung R, Davis K, Passarino G, Underhill PA, Scharfe C, Torroni A, et al.: The role of selection in the evolution of human mitochondrial genomes. Genetics 2006, I 72(I):373-387

37. Friedlaender JS, Friedlaender FR, Hodgson JA, Stoltz M, Koki G, Horvat G, Zhadanov S, Schurr TG, Merriwether DA: Melanesian mtDNA complexity. PLoS ONE 2007, 2(2):e248.

38. Hill C, Soares P, Mormina M, Macaulay V, Clarke D, Blumbach PB, Vizuete-Forster M, Forster P, Bulbeck D, Oppenheimer S, et al:: A mitochondrial stratigraphy for island southeast Asia. Am J Hum Genet 2007, 80(I):29-43.

39. Kayser M, Choi Y, van Oven M, Mona S, Brauer S, Trent RJ, Suarkia $D$, Schiefenhovel $W$, Stoneking $M$ : The impact of the Austronesian expansion: evidence from mtDNA and $Y$ chromosome diversity in the Admiralty Islands of Melanesia. Mol Biol Evol 2008, 25(7): | 362-1374.

40. Soares P, Trejaut JA, Loo JH, Hill C, Mormina M, Lee CL, Chen YM, Hudjashov G, Forster P, Macaulay V, et al: Climate change and postglacial human dispersals in southeast Asia. Mol Biol Evol 2008, 25(6): | 209- $12 \mid 8$.

4I. Lansing JS, Cox MP, Downey SS, Gabler BM, Hallmark B, Karafet TM, Norquest P, Schoenfelder JW, Sudoyo H, Watkins JC, et al.: Coevolution of languages and genes on the island of Sumba, eastern Indonesia. Proc Natl Acad Sci USA 2007, I 04(4 I): I 6022- I 6026.

42. Andrews RM, Kubacka I, Chinnery PF, Lightowlers RN, Turnbull DM, Howell N: Reanalysis and revision of the Cambridge reference sequence for human mitochondrial DNA. Nat Genet 1999 , 23(2): 147.

43. Hall TA: BioEdit: a user-friendly biological sequence alignement editor and analysis program for windows 95/98/NT. Nucleic Acids Symposium Series 1999, 4 I:95-98. 
44. Cann RL, Wilson AC: Length mutations in human mitochondrial DNA. Genetics 1983, I04(4):699-7II.

45. Handt $O$, Krings $M$, Ward $R H$, Paabo S: The retrieval of ancient human DNA sequences. Am J Hum Genet 1996, 59(2):368-376.

46. Bandelt HJ, Lahermo P, Richards M, Macaulay V: Detecting errors in mtDNA data by phylogenetic analysis. Int J Legal Med 200I, I I 5(2):64-69.

47. Lee HY, Song I, Ha E, Cho SB, Yang WI, Shin KJ: mtDNAmanager: a Web-based tool for the management and quality analysis of mitochondrial DNA control-region sequences. BMC Bioinformatics 2008, 9:483.

48. Parson W, Dur A: EMPOP--a forensic mtDNA database. Forensic Sci Int Genet 2007, I(2):88-92.

49. Behar DM, Rosset S, Blue-Smith J, Balanovsky O, Tzur S, Comas D, Mitchell RJ, Quintana-Murci L, Tyler-Smith C, Wells RS: The Genographic Project public participation mitochondrial DNA database. PLoS Genet 2007, 3(6):el04.

50. Kohl J, Paulsen I, Laubach T, Radtke A, von Haeseler A: HvrBase++: a phylogenetic database for primate species. Nucleic Acids Res 2006:D700-704.

51. Kong QP, Bandelt HJ, Sun C, Yao YG, Salas A, Achilli A, Wang CY, Zhong L, Zhu CL, Wu SF, et al.: Updating the East Asian mtDNA phylogeny: a prerequisite for the identification of pathogenic mutations. Hum Mol Genet 2006, I 5( I 3):2076-2086.

52. Trejaut JA, Kivisild T, Loo JH, Lee CL, He CL, Hsu CJ, Lee ZY, Lin M: Traces of archaic mitochondrial lineages persist in Austronesian-speaking Formosan populations. PLoS Biol 2005, 3(8): 247 .

53. Torroni A, Achilli A, Macaulay V, Richards M, Bandelt HJ: Harvesting the fruit of the human mtDNA tree. Trends Genet 2006, 22(6):339-345.

54. Bandelt $\mathrm{H}$, Forster $P$, Rohl $A$ : Median-joining networks for inferring intraspecific phylogenies. Mol Biol Evol 1999, 16(1):37-48.

55. Saillard J, Forster P, Lynnerup N, Bandelt HJ, Norby S: mtDNA variation among Greenland Eskimos: the edge of the Beringian expansion. Am J Hum Genet 2000, 67(3):71 8-726.

56. Mishmar D, Ruiz-Pesini E, Golik P, Macaulay V, Clark AG, Hosseini S, Brandon M, Easley K, Chen E, Brown MD, et al.: Natural selection shaped regional mtDNA variation in humans. Proc Natl Acad Sci USA 2003, I00(I): I7I-176.

57. Bandelt $\mathrm{HJ}$, Kong QP, Richards M, Macaulay V: Estimation of mutation rates and coalescence times: Somes caveats. In Human Mitochondrial DNA and Evolution of Homo sapiens Edited by: Bandelt HJ, Macaulay V, Richards, M. Berlin: Springer; 2006:47-90.
Publish with Bio Med Central and every scientist can read your work free of charge

"BioMed Central will be the most significant development for disseminating the results of biomedical research in our lifetime. "

Sir Paul Nurse, Cancer Research UK

Your research papers will be:

- available free of charge to the entire biomedical community

- peer reviewed and published immediately upon acceptance

- cited in PubMed and archived on PubMed Central

- yours - you keep the copyright
BioMedcentral 